\title{
Article \\ Preliminary Valorization of Climatic Conditions Effects on Curing of Air Lime-Based Mortars for Restorative Applications in the Pasargadae and Persepolis World Heritage Sites
}

\author{
Parsa Pahlavan ${ }^{1, *}$, Stefania Manzi ${ }^{2, *(\mathbb{D}, \text { Hashem Shariatmadar }}{ }^{3}$ and Maria Chiara Bignozzi $^{2}$ (D) \\ 1 Department of Architecture, Faculty of Architecture and Urban Planning, Ferdowsi University of Mashhad, \\ Mashhad 91779, Iran \\ 2 Department of Civil, Chemical, Environmental and Materials Engineering (DICAM), University of Bologna, \\ 40131 Bologna, Italy; maria.bignozzi@unibo.it \\ 3 Department of Civil Engineering, Faculty of Engineering, Ferdowsi University of Mashhad, \\ Mashhad 91779, Iran; shariatmadar@um.ac.ir \\ * Correspondence: parsa.pahlavan@um.ac.ir (P.P.); stefania.manzi4@unibo.it (S.M.); Tel.: +39-3715892467 (P.P.)
}

\section{check for}

updates

Citation: Pahlavan, P.; Manzi, S. Shariatmadar, H.; Bignozzi, M.C. Preliminary Valorization of Climatic Conditions Effects on Curing of Air Lime-Based Mortars for Restorative Applications in the Pasargadae and Persepolis World Heritage Sites. Appl. Sci. 2021, 11, 7925. https://doi.org/ 10.3390/app11177925

Academic Editor: Muhammad Junaid Munir

Received: 1 August 2021

Accepted: 25 August 2021

Published: 27 August 2021

Publisher's Note: MDPI stays neutral with regard to jurisdictional claims in published maps and institutional affiliations.

Copyright: (c) 2021 by the authors. Licensee MDPI, Basel, Switzerland. This article is an open access article distributed under the terms and conditions of the Creative Commons Attribution (CC BY) license (https:// creativecommons.org/licenses/by/ $4.0 /)$.

\begin{abstract}
Air lime mortars with addition of two types of sesame cooking oil were synthesized and cured in two different conditions: laboratory and natural climatic conditions of the Pasargadae and Persepolis World Heritage Sites. For the mortars cured in the laboratory, addition of oils in the mortar induced hydrophobic effects, but it adversely affected on permeability values and carbonation rates. However, the air lime mortars cured in the site conditions demonstrated increment in their hydrophobicity and superficial durability without retarding their setting time and adverse effects on their calcium carbonate formation values, due to various climatic parameters existing in natural outdoor conditions.
\end{abstract}

Keywords: air lime; organic additives; hydrophobicity; restorative mortars; in-situ application

\section{Introduction}

In the recent decades, conservation of the built heritage by compatible materials has become an important issue [1]. In conservation of built environment, repointing mortars are among the most important applications, as they protect the masonry in facing environmental threats [2]. Compatibility of lime-based mortars with many historical masonries has been discussed and confirmed by modern studies, thanks to their moderate stiffness and high permeability [3-5]. In fact, restorative application of historic mortars is highly recommended, as their compatibility for these applications have been frequently confirmed in the lab and in the field [6-8].

Addition of organics as historical and modern solutions have been carried out to improve the reaction of lime mortars toward water and water vapor. For instance, enhancement of lime mortars in terms of hydric properties were almost always concluded when oils were added in the mixes, in both historical solutions and modern studies [9-11]. A recent study reports that the unsaturation level of additive fatty acids is a key parameter in success for lime mortars' hydrophobization [12]. However, many studies concentrated on the mortars cured in laboratory conditions, while increment of climatic parameters in in-situ conditions might occur considerable alterations in the results.

The mortars of this study are aimed at exploring possibilities for in-situ applications in the Pasargadae and Persepolis world heritage sites (Fars province, Iran), where a great need for various types of interventions with sustainable and economic restorative mortars is reported [13]. Restoration activities in the developing countries with numerous cultural heritage sites is highly dependent on economy of conservation [14]. Added to the environmental aspects, economically feasible material solutions can broaden the conservation 
domain potentials [15-17]. Moreover, one of the principles of the ancient Persian architecture had been dependency on the materials from the site surroundings. For example, stone construction of Pasargadae and Persepolis had been dependent in terms of materials on the existing mines of the zone. The authentic construction was carried out without mortar joints. Nevertheless, due to degradation, the created gaps need to be filled with compatible mortars in order to hinder adverse environmental threats (Figure 1). In this study, aiming at respecting the essence of the historic methods, the mix-design was decided to be dependent on the site potentials (i.e., local lime, sand, and stone powders). Independent reproducibility of restorative mortars and availability of their components are crucial in historical developing countries.

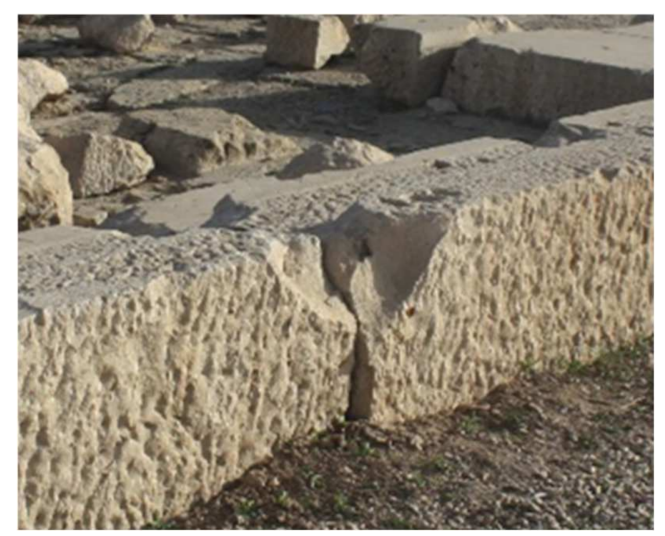

Figure 1. Stone plinths and pedestals in Pasargadae world heritage site (Fars province, Iran) in need of repointing with compatible restorative materials.

The mix-design of the current study has been delivered from previous studies and has been characterized and showed considerable enhancements in a recent study under laboratory conditions [12]. However, realizing the efficiency of the mix-design in the in-situ conditions requires a verification of the mix with local materials and at the actual in-situ climatic curing conditions. The following research assesses the lime mortars with local components in presence of two types of fatty additives (sesame and spent sesame cooking oil), in laboratory and the in-situ conditions of the designated historical site (in Fars province, Iran), simultaneously. The first aim was to assess if the probable improvement of hydric properties of lime mortars in presence of fatty acids can occur in realistic in-situ conditions with more climatic parameters compared to the laboratory. In-situ conditions can substantially affect the curing process due to climatic parameters such as air flow and daily thermal variations. The second aim was to verify if the potential hydrophobization of the mortars in the presence of the organic additives used in this study confirms the effect of their unsaturation level discussed in previous research [12]. The preliminary assessment of suitability of these mortars for in-situ applications is discussed as potential repointing materials.

\section{Materials and Methods}

The high calcium content lime putty (Calcium hydroxide) as the main component for the mortars mixes was made in the laboratory, as there is no commercial lime putty production in the country of the in-situ application (Iran). A micronized high calcium hydroxide powder as a commercial product $\left(90 \%<\mathrm{Ca}(\mathrm{OH})_{2}<93 \%\right)$, molecular weight $=74.09 \mathrm{~g} / \mathrm{mol}$, $\left(4 \%<\mathrm{CaCO}_{3}<7 \%\right)$, was slaked for 3 months with distilled water to produce lime putty with 49 wt.\% of water content, classified as CL $90 \mathrm{~S}$ according to EN 459-1 [18]. The nonreactive part of the mortars was composed by three different stone powders (dark and white sedimentary carbonate rocks and a type of sandstone) and a type of sand (particle size of 1-2 mm), from the Pulvar river (main tributary of Kor river) in Fars province, Iran (Table 1). In Pasargadae and Persepolis world heritage sites, stone surfaces in need of 
restoration with compatible materials are mostly black stone surfaces. The sand (beige) and the applied stone powders with three different colors (dark-grey, white, and green-grey) with a particle size of $\approx 10 \mu \mathrm{m}$ (through laser granulometry) were designated to perform as natural pigments with an adjustable percentage that can set the desired color and luminosity to achieve the maximum aesthetic compatibility in the in-situ applications. For the pilot mixture of the non-reactive part of the mix, the low luminosity desired for many in-situ applications close to black stones directed the formulation of this study to contain high amounts of dark stone powder, as reported in Table 1. This composition brought the desired luminosity for the tailored design of restorative mortars for repointing the joints in Pasargadae world heritage site. The appearance and luminosity of every single component of the non-reactive part of the mix is shown in Figure 2.

Table 1. The composition of the non-reactive part of the mortars.

\begin{tabular}{ccc}
\hline Non-Reactive Components & Color & wt.\% \\
\hline Dark stone powder & Dark grey & 37.5 \\
Sandstone & Green grey & 25.0 \\
White stone powder & White & 18.8 \\
Sand & Beige & 18.8 \\
\hline
\end{tabular}
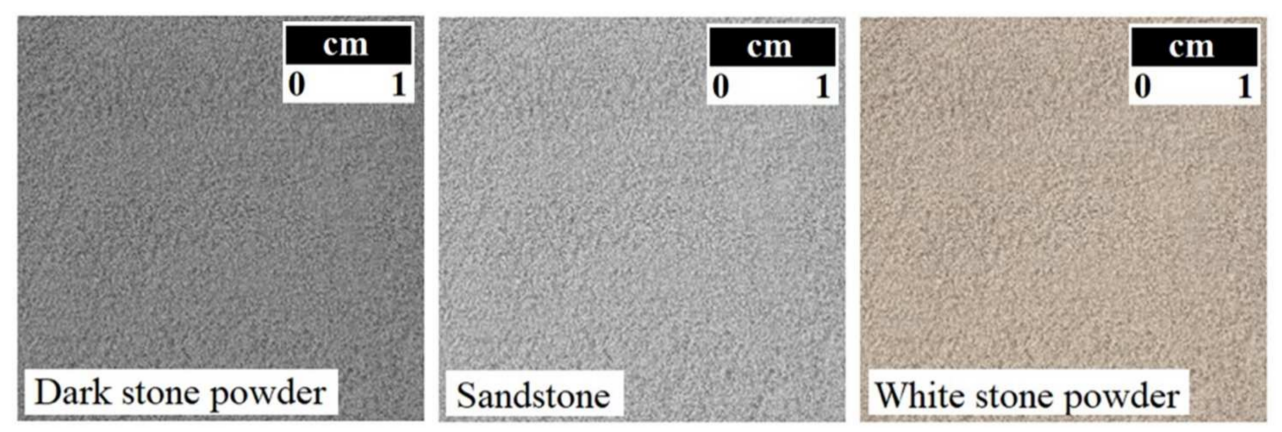

Figure 2. Various luminosities of the non-reactive powder components [colored figure].

In order to verify the potential hydric enhancements of the mortars with organic fatty acids additions with different unsaturation levels, two types of commercially produced sesame oils were used in the mixtures: sesame oil (Type 1) and spent sesame oil (Type 2), consequently with slightly different unsaturation levels and the same viscosity, were added to the mixes (Table 2). Frying operation was performed at $180{ }^{\circ} \mathrm{C}$ in laboratory conditions for $20 \mathrm{~min}$ to mimic frying at a catering level. Previous studies have revealed that increment of unsaturation level of fatty acids in oil additions to lime mortars leads to increment of hydrophobicity of the final product [12]. The substantial hydrophobicity of mortars enhanced by highly unsaturated fatty acids is reported elsewhere $[9,10,19]$. This effect had been less evident when unsaturation levels of the fatty acid's addition decreased [12]. The extent of linoleic acid in the fatty acids represents a higher unsaturation level when they include the same amount of oleic acid. The unsaturation level of sesame oil used in this study is higher compared to the spent one. In chemical terms, high-linoleic acid oils and high-oleic ones are classified as polyunsaturated fats and monounsaturated fats, respectively. Monounsaturated fats are the fatty acids that contain only one double bond in their fatty acid chain, while the polyunsaturated ones have at least two double bonds in their backbone, which facilitates the increment of hydrophobicity under the alkaline environment [12]. In this study, spent sesame oil with an inclusion of a lower amount of linoleic acids represents the additive with lower unsaturation level compared to sesame oil. 
Table 2. Significant chemical characteristic of additive oils.

\begin{tabular}{ccc}
\hline Type of Additive Oils & Oleic Acid [\%] & Linoleic Acid [\%] \\
\hline Sesame oil (Type 1) & 22.75 & 67.19 \\
Spent sesame oil (Type 2) & 22.11 & 63.22 \\
\hline
\end{tabular}

The preparation of mortars was carried out in 3 main sets of air limes mortars based on weight proportions of lime putty (Calcium hydroxide), non-reactive part, and two types of additive sesame cooking oils. In order to set the same condition for mortar preparation in the site and laboratory, no mortar mixer was used to mix the dry mixture in the lab. All the mortar samples were produced and cured in two different conditions: laboratory (abbreviated as L) and the site (abbreviated as S). The abbreviated sample names indicate the production and curing place ( $\mathrm{L}$ or $\mathrm{S})$. The types of three different formulations (A0, A1, A2) include the type of the added cooking oil ( $2 \mathrm{wt} . \%$ of the whole dry mass addition for every type) with their last letter (0: No additive oil1, 1: Oil Type 1, 2: Oil Type 2). Table 3 exhibits the mass proportional composition of mix-design and ratios among components, binders, and aggregates produced and cured in two different conditions. Hence, the six mortars studied in this research are LA0, LA1, and LA2 cured in laboratory conditions and SA0, SA1, and SA2 cured in the site ambient (Fars province, Iran). In order to obtain a desirable consistency, a fixed amount of extra distilled water was added to the mixes as a kneading water.

Table 3. Mix-design of the investigated samples.

\begin{tabular}{|c|c|c|c|c|c|c|}
\hline Sample & Mix & $\begin{array}{l}\text { Curing } \\
\text { Condition }\end{array}$ & $\begin{array}{c}\mathrm{Ca}(\mathrm{OH})_{2} \\
{[w \mathrm{t} . \%]}\end{array}$ & $\begin{array}{c}\text { Non-ReactivePart } \\
\text { [wt.\%] }\end{array}$ & $\begin{array}{l}\text { Kneading Water } \\
\text { [wt. \%] }\end{array}$ & $\begin{array}{c}\text { Oil } \\
\text { [wt.\%] }\end{array}$ \\
\hline LA0 & A0 & Laboratory & 27 & 66 & 7 & 0 \\
\hline LA1 & A1 & Laboratory & 25 & 66 & 7 & 2(Type 1$)$ \\
\hline LA2 & $\mathrm{A} 2$ & Laboratory & 25 & 66 & 7 & 2(Type 2) \\
\hline SA0 & $\mathrm{A} 0$ & In-situ & 27 & 66 & 7 & 0 \\
\hline SA1 & $\mathrm{A} 1$ & In-situ & 25 & 66 & 7 & 2(Type 1) \\
\hline SA2 & $\mathrm{A} 2$ & In-situ & 25 & 66 & 7 & 2(Type 2) \\
\hline
\end{tabular}

The binder was firstly mixed with the kneading water, then it was manually mixed with the non-reactive part manually for $3 \mathrm{~min}$. After a $20 \mathrm{~s}$ pause, the mixture was blended for an additional $3 \mathrm{~min}$ to form the mix of the reference mortar (LA0 in laboratory and $\mathrm{SA} 0$ at the site). In order to guarantee the homogenization of the oiled mixes, the sesame oils were added to mortar mixes as follows. Sesame oil and a minor portion of lime putty were mixed manually in a plastic beaker for $2 \mathrm{~min}$, and this blend was added to the rest of the mix. It was manually stirred for an extra $4 \mathrm{~min}$. Regarding the oiled mixes, a sound dispersion of the oils in the mortars was visually verified and no color alteration was observed by the naked eye.

The mortars were molded in disc-shaped plastic molds (diameter $=60 \mathrm{~mm}$, thickness $=20 \mathrm{~mm}$ ) over a thick glass surface. After $24 \mathrm{~h}$, the samples were demolded. The $\mathrm{L}$ series of the mortar samples were kept at room conditions (Temperature $=22 \pm 2{ }^{\circ} \mathrm{C}$, $\mathrm{RH}=50 \pm 5 \%$ ) for the rest of their curing period. The $\mathrm{S}$ series of mortar samples were kept in the site (temperature of the mortar production week $=8-23{ }^{\circ} \mathrm{C}, \mathrm{RH}=23 \pm 5 \%$ ). In order to increase the comparability of the characterizations with some recent studies, the mortars were firstly tested after 180 days of curing.

\section{Characterizations}

The calcium carbonate formations of the specimens were assessed by a Dietrich Fruhling calcimeter. The specimens for the assessments were taken from superficial fragments of the disc-shaped samples. The reported values are averages of 2 measurements. 
Porosity measurements by mercury intrusion porosimeter (MIP) were carried out in order to determine the values of total pore volumes and to analyze the pore size distribution of the lime mortar samples. The measurements were carried out on samples of about $0.8 \mathrm{~cm}^{3}$ using a Carlo Erba 2000 porosimeter, equipped with a macro-pore unit (Model 120, Fison Instruments, Milan, Italy) in order to obtain open porosity values and pore size distributions.

Water absorption (WA) was measured on three disc-shaped samples for each formulation. The mortar specimens were firstly dried in an oven at $100{ }^{\circ} \mathrm{C}$ for $24 \mathrm{~h}$. After cooling and mass stabilization checks, the dry mass (mdry) was registered, and samples were immersed in distilled water for $24 \mathrm{~h}$. The mass related to the "saturated surface dry condition" (mssd) was then registered. Water absorption after immersion for $24 \mathrm{~h}$ (WA24h) was then obtained as below.

$$
\mathrm{WA} 24 \mathrm{~h}=[(\mathrm{mssd}-\text { mdry }) / \text { mdry }] \times 100
$$

The vapor permeability of lime mortars was investigated after 180 days of curing. Water vapor permeability of the mortars was examined on 3 samples for each mix design. The test was performed according to EN 1015-19 [20] under controlled ambient conditions ( $\mathrm{T}=22 \pm 2{ }^{\circ} \mathrm{C}$ and $\mathrm{RH} \approx 40 \pm 2 \%$ ). The disc-shaped specimens were sealed by impermeable silicone gel on the spouts of glass containers of $\mathrm{KNO}_{3}$ saturated solutions and monitored for 30 days.

In order to test the superficial durability of the mortars as an important property for outdoor repointing and rendering applications, the 3 disc-shaped specimens for each formulation were subjected to 10 freezing-thawing cycles after 180 days of curing with the following procedure. In every single cycle the specimen were immersed in water for $30 \mathrm{~min}$ at a conditioned lab $\left(\mathrm{T}=22 \pm 2{ }^{\circ} \mathrm{C}\right.$ and $\left.\mathrm{RH}=50 \pm 5\right)$, drained over a plastic network at the same condition ( $\mathrm{T}=22 \pm 2{ }^{\circ} \mathrm{C}$ and $\left.\mathrm{RH}=50 \pm 5\right)$ for $30 \mathrm{~min}$ in order to extract the gained water, and then placed in freezer at $-20 \pm 2{ }^{\circ} \mathrm{C}$ for $3 \mathrm{~h}$. A single cycle simulates destructive circumstance in a cold environment when the trapped water inside the mortars pores freezes during the night and causes frost damage due to ice volume expansion. Through 10 freezing-thawing cycles, the condition of superficial deterioration due to visible-qualitative alterations wasassessed.

\section{Results and Discussions}

The mortars produced and cured in laboratory and site were characterized, and their open porosity (by MIP) and water absorption after $24 \mathrm{~h}$ immersion (WA24h) values are reported in Table 4. As has been already observed in previous studies, additions of oils (and usually other organics) in mortar mixes increase the formations of air voids [10,12,15]. This is normally clear from superficial formation of air bubbles when mortars are immersed in water during water absorption tests. Generally, many of these macro-pores fall out of MIP detection range (60 microns); however, they can alter water absorption and other hydric properties of the mortars. The type of additive oil in mixes did not leave a visible alteration in water absorption values when the mortars were cured in the laboratory. However, when the mortars were cured in the site conditions slightly higher unsaturation level of the oil Type 1 compared to the oil Type 2 caused higher water absorption for SA2 sample compared to SA1. The effect of unsaturation level of the fatty acids additives was deeply discussed in a previous study [12]. As a confirmation to conclusion of previous studies, additions of high-linoleic acid oils in lime mortars generally increase their hydrophobicity, toan evident extent, especially when the materials were casted and cured in in-situ conditions. The addition of sesame cooking oils in air lime mortars led to considerable hydrophobic effects such as reductions in water absorption values: $71-72 \%$ reduction when mortars were cured in laboratory and $88-93 \%$ reduction when the mortars were cured in the site conditions. 
Table 4. Physical properties of the investigated mortars: open porosity (by MIP) and water absorption (WA24h) assessed after 180 days of curing in laboratory and the site situation. The values of WA24h correspond to the average ( \pm standard deviation).

\begin{tabular}{ccc}
\hline Samples & $\begin{array}{c}\text { Open Porosity by MIP } \\
{[\%]}\end{array}$ & $\begin{array}{c}\text { WA24h } \\
{[\%]}\end{array}$ \\
\hline LA0 & 40.5 & $16.5( \pm 0.3)$ \\
LA1 & 33.2 & $4.5( \pm 0.5)$ \\
LA2 & 38.2 & $4.8( \pm 0.4)$ \\
SA0 & 35.0 & $18.1( \pm 0.3)$ \\
SA1 & 34.5 & $1.2( \pm 0.4)$ \\
SA2 & 36.6 & $1.9( \pm 0.4)$ \\
\hline
\end{tabular}

From Figure 3 it can be concluded that the curing condition did not adversely affect the pore size distribution of the mortars. A considerable challenge for in-situ application of mortars in many historical sites (including Pasargadae and Persepolis) is substantial alterations of site climatic conditions during the last decades due to climate change; hence, a single formulation cannot guaranty meeting the compatibility requirements for decades. This can be due to the fact that in these sites, the previously applied restorative mortars have been hydraulic (HL) or natural hydraulic lime (NHL) mortars. These materials need humidity for their setting and hardening actions and their initial and eventual setting and hardening phases. The addition of oils with higher unsaturation level (Type 1) significantly affected the microstructures; however, this effect was not evident in presence of the oil with lower content of linoleic acid. This confirms the observations regarding the relation between microstructure alterations and unsaturation level of fatty acids additions reported in a previous study with sunflower oil additions [12]. Figure 4 demonstrates the substantial relative humidity reduction in the driest month of the year (June) over decades in Fars province of Iran due to decreased quantity and quality of groundwater as a consequence of global warming. Hence, during the last years applications of HL and NHL, mortars did not manifest durable and compatible results in the field [13]. However, application of air lime mortars seemed to be a reliable solution in the field as they substantially need carbon dioxide for their setting and hardening. Figure 5 demonstrates increments in calcium carbonate content of the mortars when cured in the site ambient compared to laboratory curing. Generally, oil additions in lime mortars had demonstrated considerable reduction in carbonation rates. This was due to a reduction of carbon dioxide gain for cavities and surfaces [12,15]. Nevertheless, Figure 5 demonstrates proper values of carbonation for both oiled mortars and non-oiled mortars when cured in site condition. Reductions in calcium carbonation formation of mortars in addition of fatty acids were observed for laboratory cured samples and were not observed when the oiled mortars were cured in the site condition. This can be due to the fact that existence of variety of climatic parameters in the site conditions, such as air flow and daily thermal variations, eased the carbon dioxide gain for the oiled mortars; hence they behaved closely as non-oiled mortars in the site condition. This is a progressive value as addition of fatty acids usually improves the hydric properties of lime mortars with adverse effects on the carbonation rates, based on previous studies in laboratory conditions [12]. However, natural curing in the site conditions did not manifest reduction of carbonation rates for oiled mortars. 


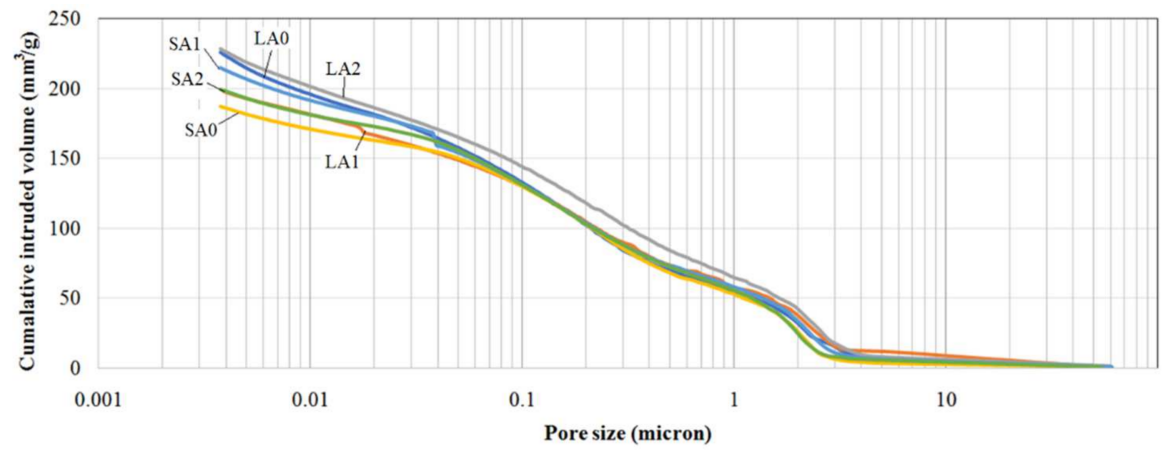

Figure 3. Pore size distribution of air lime mortars at 180 days of curing.

(a)

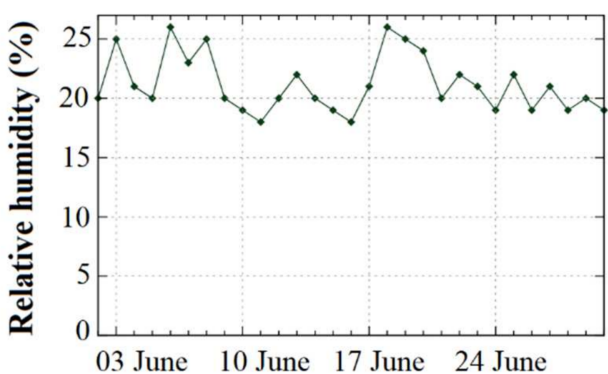

(b)

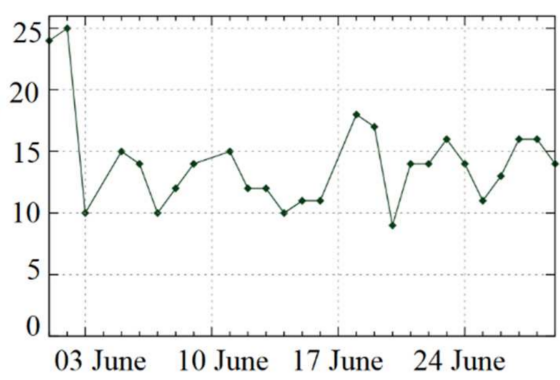

Figure 4. Substantial reduction of relative humidity [\%] of the driest month of the year in the zone of the in-situ application (Shiraz) in ten years: (a): June of 2010; (b): June of 2020 [21].

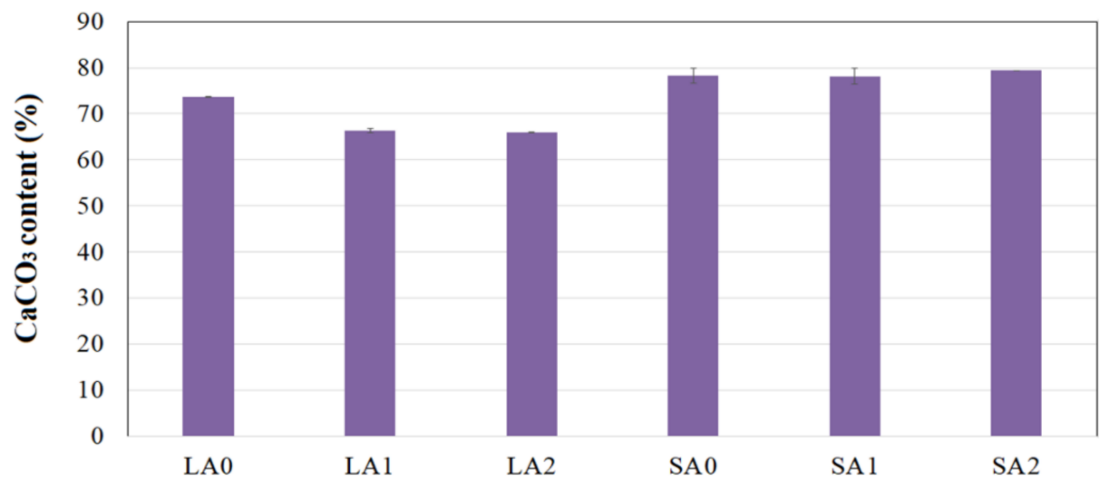

Figure 5. Calcium carbonate formation after 180 days of curing in laboratory and in the site.

Figure 6 demonstrates the impermeability (or water vapor resistance) of the mortar samples. Generally, the samples demonstrated impermeability values in the range of 4 to 5 . The results are in accordance with previously carried out studies [12,15] and all of the mortars fall in the range of 0-6 for impermeability; hence, theoretically they are considered suitable for restorative applications as their water vapor diffusion resistance coefficient value falls below 15 [22,23]. Increment of impermeability values of the mortars in presence of fatty organics can be due to their hydrophobic cavities, due to possession of lower open porosity compared to their non-oiled reference mortar demonstrated by MIP (Table 4). SA1 mortar manifested a higher permeability compared to the other samples cured in the site condition. This can be due to the high extent of its micropores, with diameters lower than 0.02 microns reported in the pore size distribution graph (Figure 3). This effect was notable only when the mortars were cured in the site conditions. In a previous study, the lime mortar samples containing higher extent of linoleic acid (13 wt.\%) demonstrated alterations in the microstructures that also led to impermeability reductions [12]. However, in this study 
this effect was evident only when the A1 mortar was cured in natural climatic condition (SA1). According to Figure 5, this can be due to the practically complete carbonation of SA1 mortar when it had outdoor curing (SA1).

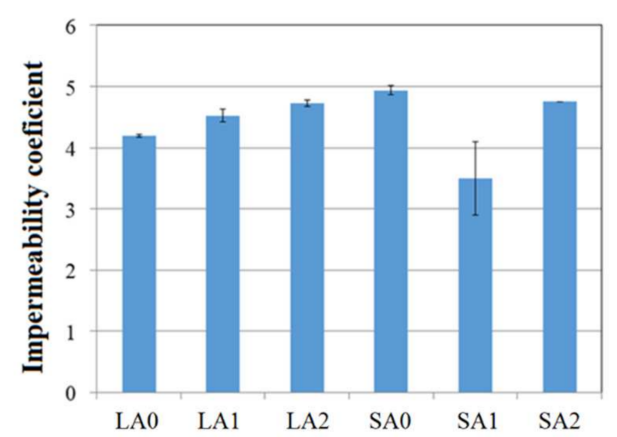

Figure 6. Impermeability of the investigated mortars at 180 days of curing.

Superficial durability of the lime mortars was assessed in freezing-thawing cycles. As a confirmation to previous studies, oiled mortars demonstrated substantially higher superficial durability compared to their non-oiled references, thanks to their low water absorption and their ability to discharge the absorbed water content before freezing due to possession of hydrophobic pores. Superficial detachments were visible for the non-oiled mortar samples cured at laboratory conditions demonstrated in Figure 7 after 5 destructive cycles. The same formulation demonstrated soundness up to 10 destructive cycles when it was cured at the site. Such an effect of curing was not reported in previous studies. This can be due to high levels of calcium carbonate formation of these mortars at outdoor curing compared to laboratory conditions demonstrated in Figure 5. Hence, in-situ cured non-oiled mortars demonstrated more superficial durability in facing freeze-thaw cycles compared to laboratory cured non-oiled mortars.

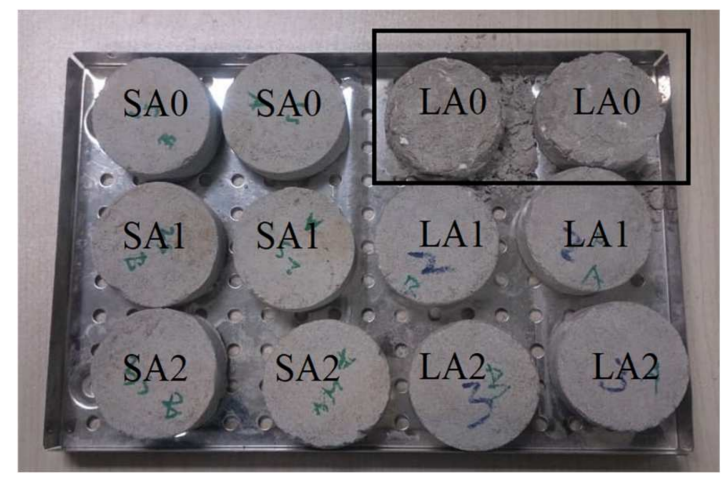

Figure 7. Lower soundness and superficial durability of LA0 compared to the other samples after 5 freezing-thawing cycles.

Bond strength is one of the most important properties of the restorative materials and a preliminary valorization check of bonding had to be placed prior to more detailed laboratorial characterizations. Bonding, strength, and durability of restorative mortars for real applications depend significantly on the substrate and its condition [24]. Bond strength depends significantly on the substrate and its condition. Therefore, the mortars were applied for repointing simulation of stones in site conditions as a preliminary assessment of their bonding potentials to assess their binding, durability, and the real pros and cons in a more realistic in-situ condition. For the studied air lime mortars with addition of sesame oil, the increment of hydrophobicity was slightly more than the reported ones with additive linseed oil [9-11] and slightly less than effect of additive sunflower oils [12]. Such differences are expected to be attributed to the difference of unsaturation level of fatty 
acids of these oil additions, as advanced hydrophobicity of lime mortars enriched by high unsaturated fatty acids is reported elsewhere [10,12,15]. All of the mortars, including the oiled samples, demonstrated soundness and no biological attack or durability issue in the first year of their in-situ monitoring. However, the mortars need longer monitoring and assessments, such as more sophisticated study of the microstructures, mechanical, and hydric properties to provide an insight about their potentials as restorative repointing materials. Such a study is being carried out, and its process and discussion will be published in a future work.

\section{Conclusions}

The following conclusions can be drawn according to the experimental findings:

- Restoration sustainability and feasibility in historical developing countries is dependent on availability of main component of the restorative mortars in these zones. Hence, production of restorative air lime mortars was carried out based on existing components in the zone of the Pasargadae and Persepolis world heritage sites.

- Addition of sesame cooking oils in air lime mortars led to considerable hydrophobic effects, such as substantial reductions in water absorption values: $71-72 \%$ reduction when mortars were cured in laboratory and $88-93 \%$ reduction when the mortars were cured in the site conditions.

- Oil additions in the air lime mortars adversely affected permeability and carbonation values when the mortars were cured in laboratory, as reported elsewhere. However, when the mortar samples were cured in natural site conditions no negative effect on carbonation and permeability values was observed due to existence of various climatic parameters in the natural site, compared to the laboratory conditions such as air flow and thermal variations. These values affected the carbon dioxide gains and microstructures, as the mortars cured in the site conditions demonstrated $78-80 \%$ of calcium carbonate after 180 days of curing.

- The effect of unsaturation level of the fatty acids as additives in hydrophobization of the mortars was evident. The oil with higher unsaturation levels demonstrated higher potentials in improving the hydric properties of the air lime mortars. However, these additions demonstrate considerable alterations in the microstructure of lime mortars.

- An improvement of hydric properties of lime mortars in the presence of fatty acids happened in realistic in-situ conditions with more climatic parameters compared to the laboratory. Existence of climatic parameters such as air flow and daily thermal variations did not demonstrate adverse effects on favorable values of the studied mortars as potential repointing materials.

- Climate change and substantial reduction of relative humidity in the recent years of the region of this application urges the use of restorative air lime mortars rather than hydraulic lime. Air lime mortars, due to low dependency on humidity of the ambient for their initial setting and hardening, have high potentials to manifest the desired durability. The addition of fatty acid organics to air lime mortars has substantially improved their hydric properties, and no biological attack or durability issue was reported in the first year of their in-situ monitoring. However, in order to complete a preliminary valorization of these mortars for sensitive restorative applications, more characterizations need to be carried out.

Author Contributions: Conceptualization and methodology, P.P., M.C.B. and S.M.; writing—original draft preparation, P.P. and S.M.; writing-review and editing, P.P., S.M.; supervision, M.C.B.; project administration, H.S. All authors have read and agreed to the published version of the manuscript.

Funding: This research received no external funding.

Institutional Review Board Statement: Not applicable.

Informed Consent Statement: Not applicable. 
Data Availability Statement: The data presented in this study are available on request from the corresponding authors.

Acknowledgments: The authors would like to thank the personnel of the Pasargadae and Persepolis World Heritage Sites for their constructive collaborations. Thanks are also due to personnel of ISCR (Istituto Superiore per la Conservazione ed il Restauro) and Association of Italian Restorers without Borders (Restauratori Senza Frontiere) active in Persepolis and Pasargadae World Heritage Sites for their precious comments and discussions.

Conflicts of Interest: The authors declare no conflict of interest.

\section{References}

1. Apostolopoulou, M.; Aggelakopoulou, E.; Siouta, L.; Bakolas, A.; Douvika, M.; Asteris, P.G.; Moropouloua, A. A methodological approach for the selection of compatible and performable restoration mortars in seismic hazard areas. Constr. Build. Mater. 2017, 155, 1-14. [CrossRef]

2. Lanzon, M.; Garcia-Ruiz, P.A. Evaluation of capillary water absorption in rendering mortars made with powdered waterproofing additives. Constr. Build. Mater. 2009, 23, 3287-3291. [CrossRef]

3. Pesce, C.; Godina, M.C.; Henry, A.; Pesce, G. Towards a better understanding of hot-mixed mortars for the conservation of historic buildings: The role of water temperature and steam during lime slaking. Herit. Sci. 2021, 9, 1-18. [CrossRef]

4. Loureiro, A.M.; Paz, S.P.; Veiga, M.d.; Angélica, R.S. Assessment of compatibility between HISTORIC mortars and limeMETAKAOLIN restoration mortars made from amazon industrial waste. Appl. Clay Sci. 2020, 198, 105843. [CrossRef]

5. Grilo, J.; Faria, P.; Veiga, R.; Silva, A.S.; Silva, V.; Velosa, A. New natural hydraulic lime mortars-Physical and microstructural properties in different curing conditions. Constr. Build. Mater. 2014, 54, 378-384. [CrossRef]

6. Thirumalini, S.; Ravi, R.; Rajesh, M. Experimental investigation on physical and mechanical properties of lime mortar: Effect of organic addition. J Cult. Herit. 2018, 31, 97-104. [CrossRef]

7. Ontiveros-Ortega, E.; Ontiveros-Ortega, A.; Moleon, J.A.; Ruiz-Agudo, E. Electrokinetic and thermodynamic characterization of lime-water interface: Physical and rheological properties of lime mortar. Constr. Build. Mater. 2017, 151, 809-818. [CrossRef]

8. Veiga, R. Air lime mortars: What else do we need to know to apply them in conservation and rehabilitation interventions? Constr. Build. Mater. 2017, 157, 132-140. [CrossRef]

9. Čechová, E.; Papayianni, I.; Stefanidou, M. Properties of lime-based restoration mortars modified by the addition of linseed oil. In Proceedings of the 2nd Historic Mortars Conference RILEM, Prague, Czech Republic, 22-24 September 2010; pp. 937-945.

10. Nunes, C.; Slížková, Z. Hydrophobic lime based mortars with linseed oil: Characterization and durability assessment. Cem. Concr. Res. 2014, 61-62, 28-39. [CrossRef]

11. Nunes, C.; Slížková, Z. Freezing and thawing resistance of aerial lime mortar with metakaolin and a traditional water-repellent admixture. Constr. Build. Mater. 2016, 114, 896-905. [CrossRef]

12. Pahlavan, P.; Manzi, S.; Rodriguez, M.T.; Bignozzi, M.C. Valorization of spent cooking oils in hydrophobic waste-based lime mortars for restorative rendering applications. Constr. Build. Mater. 2017, 146, 199-209. [CrossRef]

13. Pahlavan, P.; Fadaei, H.; Esfahani, M.R.; Shariatmadar, H. Considerations for in-situ application of sustainable restorative materials in the Pasargadae world heritage site. In Proceedings of the 5th International Conference S.ARCH-2018 9.249.1-9, Venice, Italy, 22-24 May 2018.

14. Pahlavan, P.; Manzi, S.; Sansonetti, A.; Bignozzi, M.C. Sustainable Materials for Architectural Restoration in Developing Countries: From the New Historic Mixes for the Future. In Proceedings of the International Congress on Avant-Garde Contemporary Architecture and Urbanism in Islamic Countries ACIAU 10:1-6, Mashhad, Iran, 9-10 May 2018.

15. Pahlavan, P.; Manzi, S.; Sansonetti, A.; Bignozzi, M.C. Valorization of organic additions in restorative lime mortars: Spent cooking oil and albumen. Constr. Build. Mater. 2018, 181, 650-658. [CrossRef]

16. Wei, G.; Zhang, H.; Wang, H.; Fang, S.; Zhang, B.; Yang, F. An experimental study on application of sticky rice-lime mortar in conservation of the stone tower in the Xiangji Temple. Constr. Build. Mater. 2012, 28, 624-632. [CrossRef]

17. Barreca, F.; Fichera, C.R. Use of olive stone as an additive in cement lime mortar to improve thermal insulation. Ener. Build. 2013, 62, 507-513. [CrossRef]

18. EN 459-1. Building Lime; Part 1: Definitions, Specifications and Conformity Criteria; BSI Standards Publication: London, UK, 2010.

19. Vikan, H.; Justnes, H. Influence of vegetable oils on durability and pore structure of mortals. ACI 2006, 234, 417-430.

20. EN 1015-19. Methods of Test for Mortar for Masonry, Determination of Water Vapour Permeability of Hardened Rendering and Plastering Mortars; British Standards Institution: London, UK, 1998.

21. Weather Online UK. Relative Humidity Reports for Shiraz July 2010-July 2020. Available online: https:/ / www.weatheronline.co. uk/ (accessed on 5 August 2020).

22. Moropoulou, A.; Bakolas, A.; Moundoulas, P.; Aggelakopoulou, E.; Anagnostopoulou, S. Optimization of compatible restoration mortars for the earthquake protection of Hagia Sophia. J. Cult. Herit. 2013, 14, e147-e152. [CrossRef] 
23. European Standard EN998-1. Specification for Mortar for Masonry-Part1: Rendering and Plastering Mortar; BSI Standards Publication: London, UK, 2010.

24. Luso, E.; Lourenço, P.B. Bond strength characterization of commercially available grouts for masonry. Constr. Build. Mater. 2017, 144, 317-326. [CrossRef] 